\title{
The prevalence of body dysmorphic disorder among South African university students
}

\author{
A Dlagnikova, ${ }^{1}$ MA (Clinical Psychology); R L van Niekerk, ${ }^{2}$ D Lit et Phil (Psychology) \\ ${ }^{1}$ Department of Psychology, Faculty of Humanities, University of Johannesburg, South Africa \\ ${ }^{2}$ Department of Human Movement Science, Faculty of Science and Agriculture, University of Fort Hare, Alice, South Africa
}

Corresponding author: R L van Niekerk (leonvn@ufh.ac.za)

Background. The prevalence of body dysmorphic disorder (BDD) among South African students is explored in this article. BDD is regarded as an obsessive-compulsive-related disorder characterised by a preoccupation with one or more perceived defects or flaws in physical appearance and expressed in repetitive behaviours or mental acts as a response to the appearance concerns, causing clinically significant distress or impairment in functioning.

Objectives. To determine the prevalence of BDD among undergraduate students $(N=395)$ at an inner-city university.

Methods. Proportionate stratified random cluster sampling was used to select the sample. The students completed a demographics survey and the Body Image Disturbance Questionnaire.

Results and conclusion. An overall prevalence rate of $5.1 \%$ was found in this study, which is similar to prevalence rates reported in existing literature among student populations. No clinically significant differences in the severity of the BDD were found on the demographic variables of gender, race or sexual orientation. However, students differed significantly in their experience of the severity of the disorder in terms of age, in that students over the age of 21 reported higher severity levels than students under the age of 21 . Although the prevalence of the disorder compares with that in other countries, its severity seems to increase with age among South African students.

S Afr J Psychiatr 2015;21(3):104-106. DOI:10.7196/SAJP.8251

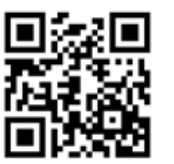

Body dysmorphic disorder (BDD) was previously classified in the Diagnostic and Statistical Manual of Mental Disorders, 4th edition, text revision (DSMIV-TR $)^{[1]}$ as a somatoform disorder characterised by a preoccupation with a slight or imagined defect in one's appearance, leading to clinically significant distress or impairment in functioning. Owing to several issues that have been raised regarding the disorder's status in DSM-IV-TR, it is currently classified as an obsessive-compulsive-related disorder in the Diagnostic and Statistical Manual of Mental Disorders, 5th edition (DSM-5). ${ }^{[2]}$ BDD is defined in DSM-5 $5^{[2]}$ as a preoccupation with perceived defects or flaws in physical appearance which present with repetitive behaviours or mental acts as a response to the appearance concerns.

The prevalence of BDD is unclear. A large variability in data with the differing samples, methodology and research objectives exists. Some researchers ${ }^{[3]}$ point out that there is a lack of literature examining the prevalence of BDD in student samples and that most studies either include women or gender as their only variables. Consequently, they ${ }^{[3]}$ contributed by including ethnicity and sexual orientation as variables. Existing prevalence studies may be inapplicable to the South African (SA) context because they are predominantly European and American. ${ }^{[4]}$ In studying the prevalence and demographic differences in BDD, high-risk groups can be identified which in turn guide prevention and treatment. ${ }^{[4]}$ Current research reporting on patients visiting dermatologists or plastic surgeons often underestimates true prevalence figures; ${ }^{[5]}$ therefore, examining BDD in clinical samples only distorts true prevalence rates in populations. Clinical studies conducted on psychiatric populations and individuals seeking cosmetic and dermatological treatment found the prevalence of BDD among psychiatric patients to be between $0.8 \%$ and $16 \%$ of the population. ${ }^{[6,7]}$ Demographic differences among the groups in these studies are unclear; however, available research indicates a higher prevalence rate among females. ${ }^{[6,7]}$ Among cosmetic and dermatological patients, findings indicate that BDD is highly prevalent (up to $33 \%$ ). ${ }^{[8-10]}$ The prevalence in community samples, however, seems to be lower, from $0.7 \%{ }^{[11]}$ to $2.4 \%{ }^{[12]}$ with females showing higher prevalence rates than males. ${ }^{[12]}$

The prevalence of BDD among student populations ranges from $2.3 \%$ in Australia, ${ }^{[4]}$ to $5.3 \%$ in Germany, ${ }^{[13]} 4.8 \%$ in Turkey, ${ }^{[5]} 4.9 \%$ in China ${ }^{[14]}$ and $4.9 \%$ at an American university. ${ }^{[3]}$ These researchers reported higher prevalence of BDD among male students. Compared with the general population, these studies suggest that BDD is more prevalent among students. This may be a reflection of differences in methodology, the possibility that prevalence is rising among students or because students are more willing to disclose their BDD. There is also a clear difference in gender between community samples and student samples, with the community studies reporting a consistently higher prevalence among females. Perhaps age is a relevant variable, since students tend to have a younger mean age than participants from community studies. It is possible that BDD affects both genders indiscriminately during the late teens or early twenties and over time begins to affect more women than men. Studies that include a large age range are needed in order to explore this hypothesis.

In addition to measuring gender differences in BDD, some studies ${ }^{[3,4]}$ included racial differences in their studies. Bartsch ${ }^{[4]}$ found that 
dysmorphic concern was lower among Asian Australian students than among white Australian students, while Boroughs et al. ${ }^{\left[{ }^{[3]}\right.}$ found a lower level of concern among African American women than white and Latina women. The latter study proceeded to examine differences in sexual orientation as well, indicating that BDD was higher among gay and lesbian students than among heterosexual students.

In summary, some variability in the prevalence of BDD among student populations has been shown in studies across various countries. Furthermore, the inclusion of more variables in the study of prevalence rates and group differences contributed to a more nuanced understanding of BDD beyond gender. Therefore, the core questions of this study are to determine what the prevalence of BDD is within an SA university student sample and to report on any group differences for gender, race and sexual orientation.

\section{Methods \\ Sample}

A proportionate stratified random cluster sample of 395 undergraduate students (mean (standard deviation (SD)) age of 20.02 (2.45) years) across nine faculties at an inner-city university participated in the study. In order to ensure optimal representation within the current study, the researchers employed a method which entails that different groups or clusters are drawn at random, with an equal distribution of participation in each academic year. The number of students selected in the sample was proportionally representative of the number of undergraduate students for each year group and faculty at the university. Thus, a number of students from various academic modules at undergraduate level, in proportion to the faculty size, were drawn at random from each of the nine faculties at the university. Permission from the lecturers and informed consent from the students were obtained in written form. Ethical clearance for the study was provided by the Academic Ethics Committee of the Faculty of Humanities, University of Johannesburg.

\section{Data collection}

The participants were asked to complete a demographic questionnaire, including items such as age, sex, race, and first year of registration, current academic year and sexual orientation. They were also asked to complete the Body Image Disturbance Questionnaire (BIDQ) ${ }^{[15]}$ The BIDQ consists of seven twopart items on a five-point Likert scale. Three of the total 14 items require open-ended responses. The first two questions assess the level of concern with an appearance feature, the third question assesses the degree of subjective distress, and the rest of the items determine the level of functional impairment in different areas. The norm scale indicated that a raw score of 21 or higher on the BIDQ would be indicative of BDD. High internal consistency was found for the BIDQ, with a Cronbach's alpha of $0.89-0.90$ for women and $0.87-0.89$ for men, as well as a testretest reliability of $0.88{ }^{[15]}$ As an adjunct, the researchers included a question to determine whether the appearance feature about which the participant is most concerned is weightrelated. This was done to control for weight concerns as a factor in the prevalence of BDD.

\section{Data analysis}

The variables were measured using descriptive statistics. The relationship between continuous variables was determined by calculating Pearson product moment correlations. Relationships between categorical variables (gender, age groups, race, and sexual orientation) and the prevalence of BDD were determined using $\chi^{2}$ analyses. Independent sample $t$-tests and analysis of variance (ANOVA) were used to determine group differences with continuous variables. The prevalence of BDD is reported as the percentage of participants with BDD relative to the total population of students who participated in the study.

\section{Results}

A total of 395 students were included in the sample. Most of the students were from the Faculty of Economic and Financial Sciences ( $n=94 ; 23.7 \%$ ), followed by students from the
Faculty of Engineering ( $n=68 ; 17.2 \%)$, the Faculty of Science $(n=67 ; 17.0 \%)$, the Faculty of Humanities $(n=55 ; 13.9 \%)$ and the Faculty of Education $(n=32,8.1 \%)$. The Faculties of Health $(n=29,7.3 \%)$, Management $(n=28$, 7.1\%), Art, Design and Architecture ( $n=11$, $2.8 \%)$ and Law $(n=11,2.8 \%)$ had the least representation.

The largest part of the sample consisted of first-year students ( $n=256 ; 64.8 \%)$, followed by second-years $(n=103,26.1 \%)$ and third-years $(n=33,8.4 \%)$. Only four students $(1.0 \%)$ were in their fourth year (as some undergraduate courses are 4-year courses). Participants' ages ranged between 18 and 23 years of age, with a mean (SD) age of 20.02 (2.45) years. Most of the participants were female ( $n=235 ; 59.5 \%$ ).

The racial distribution in the sample represented black $(n=257 ; 65.1 \%)$, white $(n=89 ; 22.5 \%)$, Asian $(n=25 ; 6.3 \%)$ and students of mixed descent $(n=19 ; 4.8 \%)$. These racial proportions are representative of the population of students at the university.

The sexual orientation of the participants was predominantly heterosexual $(n=375$; $94.9 \%)$, while $8(2.0 \%)$ described themselves as gay or lesbian and $6(1.5 \%)$ as bisexual. Six (1.5\%) responded with 'other', possibly indicating that they are asexual or that they are uncertain of their sexual orientation.

\section{Prevalence of BDD}

While BDD was not found in most of the students $(n=350 ; 88.6 \%)$, the prevalence of BDD, presented in Table 1, was reported at $5.1 \%$ $(n=20)$. Although 24 students (6.1\%) met the cut-off score for BDD on the BDIQ (score >21), they were excluded as their primary concern was limited to weight concerns. Most of the students excluded because of weight concerns were female $(n=18 ; 75.0 \%)$. However, more males $(n=11 ; 55.0 \%)$ than females $(n=9 ; 45.0 \%)$ were found to have BDD.

\section{Table 1. Prevalence of BDD}

\begin{tabular}{lllllll}
\hline Category & $\begin{array}{l}\text { Age (years), } \\
\text { mean (SD) }\end{array}$ & $\begin{array}{l}\text { Total BDD } \\
\text { score, } \\
\text { mean (SD) }\end{array}$ & $\begin{array}{l}\text { BDD } \\
\text { score, } \\
\text { mean (SD) }\end{array}$ & $\begin{array}{l}\text { Total, } \\
\boldsymbol{n}(\%)\end{array}$ & Gender & $\boldsymbol{n}(\%)$ \\
\hline No BDD & $19.96(2.42)$ & $11.76(3.64)$ & $1.59(0.52)$ & $350(88.4)$ & Male & $143(40.9)$ \\
& & & & Female & $207(59.1)$ \\
$\begin{array}{l}\text { Participants } \\
\text { excluded due to } \\
\text { weight concerns }\end{array}$ & $20.45(2.67)$ & $24.21(3.31)$ & $3.34(0.51)$ & $24(6.1)$ & Male & $6(25)$ \\
$\begin{array}{l}\text { Participants } \\
\text { with BDD }\end{array}$ & $20.55(2.64)$ & $24.35(3.01)$ & $3.45(0.42)$ & $20(5.1)$ & Male & $11(55)$ \\
& & & & & Female & $9(45)$
\end{tabular}




\section{Students with BDD}

Fifty per cent of students $(n=10)$ with BDD were in their first year, while $8(40.0 \%)$ were in second year and $2(10.0 \%)$ were third-year students. This implies that $3.91 \%$ of the first years participating in the study had BDD, while $7.77 \%$ of second years and $6.06 \%$ of third years had BDD. There was a tendency for BDD severity score to increase with each year group, with mean (SD) scores of 3.27 (0.27) for first-years, $3.63(0.50)$ for second-years and $3.93(0.30)$ for third-year students $(p=0.057)$.

Prevalence of BDD was higher among late adolescents (up to 21 years of age) $(n=12 ; 60.0 \%)$ than young adults ( $\geq 21$ years of age) $(n=8 ; 40 \%)$. However, the latter group reported significantly higher severity rates than the former (young adults: $M=3.78$ (0.41); late adolescents: $M=3.27$ (0.31); $p=0.005)$.

Although more male students $(n=11 ; 55.0 \%)$ were found with BDD than female students, no significant difference in the severity of the BDD was found for gender (males: $M=3.58$ (0.44); females: $M=3.34$ $(0.11) ; p=0.234)$. Similarly, no differences were found in terms of prevalence of BDD across racial groups $(p=0.187)$ or groups with different sexual orientations $(p=0.115)$.

\section{Discussion}

A prevalence rate of approximately 5\% for BDD was found in this study. This is similar to most of the prevalence rates found among German, American, Turkish, Pakistani and Chinese student populations. ${ }^{[3,5,13,14]}$ However, the prevalence was higher than the $2.3 \%$ found in a sample of Australian students. ${ }^{[4]}$ This may have been due to the use of convenience sampling in the Australian study.

No statistically significant differences were found for either the prevalence rates of BDD or the severity of BDD among the two gender groups. This is similar to the finding among Chinese students, ${ }^{[14]}$ but contrary to the results reported in other studies, ${ }^{[3,4,13]}$ where higher prevalence rates were found among female students. No statistically significant differences in the severity of symptoms between male and female students were found, which corresponded with the findings among Chinese students. ${ }^{[14]}$ However, three studies reported higher severity levels of BDD among female students. ${ }^{[3,4,13]}$ Results are therefore still inconclusive for gender differences in a student population.

No statistically significant differences in the prevalence rates or severity of BDD were found among racial groups. This is contrary to two recent studies ${ }^{[3,4]}$ where the prevalence and severity of BDD were highest among white students. According to Wolrich, ${ }^{[16]}$ the higher prevalence found among the white population (including general communities and clinical populations) may have been a reflection of the large proportion of white participants in the samples used. However, the sample in the current study comprised mostly black students and the prevalence of BDD was still higher among white students. While the difference is not statistically significant, it provides provisional support for existing research that the disorder tends to be more prevalent among white students.

Both the current study and a study among American students ${ }^{[3]}$ found no differences between students with different sexual orientation. In the current study, there was only one gay or lesbian student with BDD and thus the findings should be interpreted with caution. Since only one other study has included sexual orientation as a variable in their analysis, more research is needed in order to explore this trend.

A significant difference in the severity of BDD was found among the age groups. Students over the age of 21 (young adults) experience more severe BDD than those younger than 21 (late adolescents). A reason could be found in the development tasks of young adults, a period during which intimate relationships are formed with a threat of becoming isolated because of fear of rejection. ${ }^{[17]}$ Perhaps young adult students experience more pressure to establish long-term romantic relationships than do students who have recently begun university, and this may have contributed to their developing a preoccupation with their appearance. The longer duration of BDD in young adults could also be an explanation of the higher severity of BDD as a longer duration of the illness predicted a lower likelihood of remission from $\mathrm{BDD}^{[18]}$ In order to fully explore these differences in age, qualitative research is needed.

\section{Conclusion}

The prevalence of BDD and group differences among SA students are to a large extent comparable with other studies in student populations. It seems however, that the difference between groups in this population is more related to age, specifically during the transition into young adulthood, when finding a partner becomes important. Owing to the sparse literature of studies reporting BDD among SA populations, further studies are needed in general communities, as well as in clinical populations.

\section{References}

1. American Psychiatric Association. Diagnostic and Statistical Manual of Mental Disorders. 4th ed., text revision. Washington, DC: American Psychiatric Association, 2000:466-469.

2. American Psychiatric Association. Diagnostic and Statistical Manual of Mental Disorders. 5th ed. Washington, DC: American Psychiatric Association, 2013:242-247.

3. Boroughs MS, Krawczyk R, Thompson JK. BDD among diverse racial/ethnic and sexual orientation groups: Prevalence estimates and associated factors. Sex Roles 2010;63(9):725-737. [http://dx.doi.org/10.1007/s11199-010-9831-1]

4. Bartsch D. Prevalence of BDD symptoms and associated clinical features among Australian university students. Clin Psych 2007;11(1):16-23. [http://dx.doi. org/10.1080/13284200601178532]

5. Cansever A, Uzun O, Dönmez E, Ozşahin A. The prevalence and clinical features of BDD in college students: A study in a Turkish sample. Compr Psychiatry 2003;44(1):60-64. [http:// dx.doi.org/10.1053/comp.2003.50010]

6. Conroy M, Menard W, Fleming-Ives K, Modha P, Cerullo H, Phillips KA. Prevalence and clinical characteristics of BDD in an adult inpatient setting. Gen Hosp Psychiatry 2008;30(1):67-72. [http://dx.doi.org/10.1016/j.genhosppsych.2007.09.004]

7. Kollei I, Martin A, Rein K, Rotter A, Jacobi A, Mueller A. Prevalence of BDD in a German psychiatric inpatient sample. Psychiatry Res 2011;189(1):153-155. [http://dx.doi.org/10.1016/j.psychres.2011.02.009]

8. Conrado LA, Hounie AG, Diniz JB, et al. BDD among dermatologic patients: Prevalence and clinical features. J Am Acad Dermatol 2010; 63(2):235-243. [http://dx.doi.org/10.1016/j.jaad.2009.09.017]

9. Calderón P, Zemelman V, Sanhueza P, Castrillón M, Matamala J, Szot J. Prevalence of BDD in Chilean dermatological patients. J Eur Acad Dermatol Venereol 2009;23(11):1328. [http:// dx.doi.org/10.1111/j.1468-3083.2009.03154.x]

10. Picavet VA, Prokopakis EP, Gabriëls L, Jorissen M, Hellings PW. High prevalence of BDD symptoms in patients seeking rhinoplasty. Plast Reconstr Surg 2011;28(2):509-517. [http:// dx.doi.org/10.1097/PRS.0b013e31821b631f]

11. Otto MW, Wilhelm S, Cohen LS, Harlow BL. Prevalence of BDD in a community sample of women. Am J Psychiatry 2001;158(12):2061-2063. [http://dx.doi.org/10.1176/appi.ajp.158.12.2061]

12. Koran LM, Abujaoude E, Large MD, Serpe RT. The prevalence of BDD in the United States adult population. CNS Spectrums 2008;13(4):316-322. http://www.cnsspectrums.com/ (accessed 25 September 2013)

13. Bohne A, Keuthen NJ, Wilhelm S, Deckersbach T, Jenike MA. Prevalence of symptoms of BDD and its correlates: A cross-cultural comparison. Psychosomatics 2002;43(6):486-490. http:// psychosomaticsjournal.org/ (accessed 25 September 2013)

14. Zhu H, Deng Y. The prevalence of the BDD among undergraduate students in Hainan (Abstract). Journal of Hainan Medical College 2010;1:123-126.

15. Cash TF, Phillips KA, Santos MT, Hrabosky JI. Measuring 'negative body image': Validation of the Body Image Disturbance Questionnaire in a nonclinical population. Body Image 2004;1(4):363-372. [http://dx.doi.org/10.1016/j.bodyim.2004.10.001]

16. Wolrich MK. BDD and its significance to social work. Clinical Social Work Journal 2011;39(1):101-110. [http://dx.doi.org/10.1007/s10615-010-0289-y]

17. Erikson EH. Childhood and Society. New York, NY: Norton, 1963.

18. Phillips KA, Pagano ME, Menard W, Fay C, Stout RL. Predictors of remission from body dysmorphic disorder: A prospective study. J Nerv Ment Dis 2005;193(8):564-567. 